\title{
Précis of The Illusion of Doubt
}

\author{
Genia Schönbaumsfeld \\ Department of Philosophy, University of Southampton, \\ Southampton, United Kingdom \\ G.M.E.Schoenbaumsfeld@soton.ac.uk
}

\begin{abstract}
The Illusion of Doubt shows that radical scepticism is an illusion generated by a Cartesian picture of our evidential situation - the view that my epistemic grounds in both the 'good' and the 'bad' cases must be the same. It is this picture which issues both a standing invitation to radical scepticism and ensures that there is no way of getting out of it while agreeing to the sceptic's terms. The sceptical problem cannot, therefore, be answered 'directly'. Rather, the assumptions that give rise to it, need to be undermined. These include the notion that radical scepticism can be motivated by the 'closure' principle for knowledge, that the 'Indistinguishability Argument' renders the Cartesian conception compulsory, that the 'New Evil Genius Thesis' is coherent, and the demand for a 'global validation' of our epistemic practices makes sense. Once these dogmas are undermined, the path is clear for a 'realism without empiricism' that allows us to re-establish unmediated contact with the objects and persons in our environment which an illusion of doubt had threatened to put forever beyond our cognitive grasp.
\end{abstract}

\section{Keywords}

radical scepticism - Cartesian picture - Reasons Identity Thesis - New Evil Genius Thesis - closure principle

My book, The Illusion of Doubt, shows that radical scepticism is an illusion generated by a Cartesian picture of our evidential situation - the view that my epistemic grounds in both the 'good' and the 'bad' cases must be the same, and consists in information about an inner mental realm of experience from which I must try to work my way out to what goes on 'out there' in the 'external world'. It is this picture which issues both a standing invitation to radical scepticism and ensures that there is no way of getting out of it while agreeing 
to the sceptic's terms. What we therefore need to do is not try to answer the sceptical problem 'directly', but rather to undermine the assumptions that it depends on. These are among the most ingrained assumptions in contemporary epistemology. They include the notion that radical scepticism can be motivated by the 'closure' principle for knowledge, that the 'Indistinguishability Argument' renders the Cartesian conception compulsory, that the 'New Evil Genius Thesis' is coherent, and the demand for a 'global validation' of our epistemic practices makes sense. Once these dogmas are undermined, however, the path is clear for a 'realism without empiricism' that allows us to re-establish unmediated contact with the objects and persons in our environment which an illusion of doubt had threatened to put forever beyond our cognitive grasp.

The book is composed of an introduction, five chapters, and a conclusion. In Chapter One, I attack the commonly accepted assumption that we need to find a solution to 'closure-based' sceptical arguments, and, hence, to the 'scepticism or closure' dilemma. I show that this is mistaken, as the closure principle does not, in fact, do real sceptical work. Rather, the decisive, scepticism-friendly moves are made before the closure principle is even brought into play. If we cannot avoid the sceptical conclusion, this is not due to closure's holding it in place, but because we've already been persuaded to accept a certain conception of perceptual reasons: the 'default view' which contends that in both the good case and the bad case my perceptual grounds are the same (call this the Reasons Identity Thesis [RIT]).

Most epistemologists believe that this view is an inescapable consequence of the Indistinguishability Argument, but this is false. From the fact that one is not able introspectively to distinguish between the good case and the bad case, it does not follow that all one can ever have is appearance-based reasons. Consequently, an alternative path is open to us: If we reject RIT, we can endorse a form of disjunctivism according to which good-case perceptual reasons are factive and knowledge-entailing. This not only prevents radical scepticism from arising in the first place, but also shows that it is not the closure principle that forces the sceptical conclusion upon us. For, as Chapter Two reveals, it is prior acceptance of the Reasons Identity Thesis that makes the world recede behind a 'veil of appearances', and therefore endorsement of the default view that sets us on the path towards thinking that we can never know what lies behind the 'veil'. The closure principle, by contrast, is entirely innocent in the whole affair, as it only comes into play after one has already conceded knowledge, or concluded that this isn't possible.

If this is right, then radical scepticism is not the unavoidable consequence of an intuitive argument, but the product of faulty theorizing. What is more, 
from the fact that we can sometimes be misled-that bad cases are possible-it does not follow that this thought generalizes: that what sometimes happens, could always happen, and, hence, that there might be no good case (bar a 'hypothetical' one) at all. In order to see this, however, we need to distinguish between two different kinds of sceptical scenario that are usually not distinguished in the contemporary literature: 'local' brain-in-a-vat (BIV) scenarios (forms of 'recent envatment', for example) and 'global' ones that attack the very idea that anyone has ever had perceptual contact with an 'external' thing. I argue that 'local' BIV scenarios work in a similar way to arguments from perceptual illusion in the sense that both must presuppose the existence of an 'external world', and the in-principle veridicality of perceptual experience, in order to get off the ground. Consequently, such scenarios are not powerful enough to make radical scepticism (the thought that all our perceptual beliefs might be false) compulsory.

'Global' вIV scenarios, on the other hand, operate on a metaphorical, not a literal level (as recent envatment scenarios do), and are an expression of the anxiety that perception as such might be unable to 'make contact' with the 'external world' at all. Since local sceptical scenarios cannot be 'aggregated' to imply radical scepticism, however, it is not easy to see why we should endorse the idea that all of our perceptual beliefs taken together could fail to 'match' the way the world is. Hence, our willingness nevertheless to entertain such a notion is not driven by plausible, independent arguments, but rather by the thought that we are somehow not in direct touch with the objects that make up the physical world, but only with our sense-experiences or mental states from which we must infer the existence of the 'external world'. It is this conception - call it the Cartesian Picture of our epistemic situation - that gives rise to the default view by making us believe that appearance-based perceptual reasons are the best we can possibly have, since the world itself is always just beyond our perceptual grasp. But there is no good independent reason to endorse this picture, and the Indistinguishability Argument alone does not imply it. That is to say, subjective indistinguishability (of the good and the bad case) does not imply the Reasons Identity Thesis, and consequently, we do not need to accept the thought that unless we can already rule out in advance that we are not radically deceived, we cannot really know anything.

In Chapter Three, I show that proponents of the default view take it for granted that it is possible to know how things subjectively seem to one, even though it is conceivable that one's perceptual experiences as a class may never be experiences of anything 'external'. Hence, on this conception, 'appearances' must be thought to have a determinate content which one can be presented with in sense-experience-for example, an appearance 'as of there being a 
cookie in front of one' as opposed to an appearance 'as of there being a computer on the table' - even though there might be no physical objects (such as cookies and computers) at all. This way of conceiving of one's epistemological situation presupposes that the content of one's experiences is completely detachable from what these experiences are putatively experiences of, and, consequently, that one can know the content that one is presented with in sense-experience-say 'seeing books on the table'-without thereby necessarily coming to know anything at all about what these experiences reveal about the physical world itself (including if there is one).

It seems clear that such a conception of experience is the 'intuition' behind the 'New Evil Genius Thesis': the thought that the experiences that I share with my 'envatted' counterpart, and that I base my perceptual knowledge on, are, in all relevant 'internal' respects, the same. For if this thesis is coherent, it entails that one's putative knowledge-claims about the world can be derived solely from knowledge of how things appear to one, since unless one can rule out that one is in the 'global' 'vat-world', one can never have knowledge of anything else. Given that it must be possible to express these alleged 'knowledge-claims' in a language (if they are to be expressed at all), this conception further implies that a language must be possible that does not presuppose any acquaintance with an 'external world', or with 'other minds', since if we were in the 'global' 'vat-world', there would be no such things. Consequently, the words of this language would have to derive their meaning purely from being linked to episodes of one's own consciousness (since there may be nothing else), which means that it must be possible to identify and describe these episodes independently of whether they ever inform one of 'reality' or of 'the facts'. Drawing on Wittgenstein's anti-private language considerations, I show that this is in fact impossible: there can be no such thing as meaning and belief ascription in the 'global' sceptical scenario, because no logically private 'vat-language' can be constructed. So, the radical sceptic cannot have it both ways here: she cannot hang on to the notion that knowledge of the content of one's sense-experiences is possible, while at the same time maintaining that knowledge of the 'external world' is forever foreclosed. This constitutes the final nail in the coffin for the default view.

In Chapter Four, the notion that radical scepticism might coherently challenge us to provide a 'global validation' of our entire epistemic system comes under critical scrutiny. Making use of insights from Wittgenstein's On Certainty, I show that the required 'proof' of the external world's existence would not only be circular, but logically impossible in the sense that one could not even coherently state the radical sceptic's challenge if radical scepticism were true. For if, in an ordinary context, I could, for example, be 'wrong' about having 
hands, then this would be no ordinary 'mistake', but would rather constitute what Wittgenstein calls 'an annihilation of all yardsticks': it would undermine the coherence of the very practices on which my expression of doubt at the same time depends (since if there were no such practice, there would be no such doubt). Doubt, in other words, needs a context, a common human background that stands fast and against which specific epistemic claims can be assessed. A 'global' doubt is a paper doubt, as it tries to doubt everything at the same time and in this way fails to doubt at all. Consequently, neither a 'validation' nor an 'invalidation' of all of our epistemic practices taken together makes sense.

If this is correct, then we don't stand in an epistemic relation-groundless or otherwise - to what has come to be known as 'hinge propositions': those propositions that are exempt from doubt and that constitute the 'hinges' around which our enquiries turn. In the remainder of the chapter, I show how my proposal differs from - and avoids some of the problems of - the two most influential ways of interpreting the 'hinge' passages: the 'quasi-epistemic' reading that seeks to downplay the radical nature of Wittgenstein's conception by assimilating his thought to more mainstream epistemological views, and the non-epistemic, 'quasi-pragmatic' interpretation that goes too far in the opposite direction by equating 'hinge propositions' with a type of 'animal' certainty. Neither strategy, I argue, is promising for the reason that 'hinges' are best not conceived as certainties (or uncertainties) at all. Rather, what Wittgenstein says in respect to them is that doubt is 'logically' excluded. And where there can be no doubt, I contend, there is no such thing as knowledge or certainty either.

Chapter Five defends a 'realism without empiricism'. This is the view that once the global sceptical scenario has been exposed as an illusion, nothing stands in the way of conceiving of perceptual warrant (in good cases) as conclusive, and thus as providing us with knowledge of an objective, mind-independent world. I consider how the more modest 'realism without empiricism' differs from 'hyper-realism', and why one should endorse the former, while eschewing the latter. I then go on to consider the question whether the position that I defend results in an objectionable form of relativism. For one might worry that as different cultures and societies may accept different background principles and standards of evaluation, if these are all thought to be equally groundless, there can be no way of settling which set of standards is correct and, consequently, whose knowledge-claims are true. I show that this concern is misplaced: if a community is acknowledging the same data, then they are already broadly conceptualizing like us, and, hence, any disagreement we might have with them is bound to be essentially 'local' (i.e., they are not 
going to reject our fundamental principles). If, on the other hand, it seems that a community is 'radically disagreeing' with us, then it is likely, as in the case of Wittgenstein's strange 'wood-sellers', that they are operating with concepts very different from ours. So, it would be misleading to say in this case that they are acknowledging the same data, or, indeed, that they are, in the relevant sense, disagreeing with us (for in order to disagree, one must operate with broadly similar concepts). In other words, if others think differently than us while sharing the same concepts, we or they (or neither of us) must be right. If we don't share the same concepts, on the other hand, then there is also no room for genuine disagreement ('faultless' or otherwise). Hence, 'realism without empiricism' undermines epistemic relativism and does not support it. 